\section{Edycaçãa



ARTIGO

\section{Editor}

Alexandre Anselmo Guilherme PUCRS, RS, Brasil

\section{Editor Assistente}

Cibele Cheron

PUCRS, RS, Brasi

\section{Editores Associados}

Bruno Antonio Picoli

Universidade Federal da Fronteira Sul, Chapecó, SC, Brasil

Pricila Kohls dos Santos Universidade Católica de Brasília, Brasília, DF, Brasil

Renato de Oliveira Brito

Universidade Católica de Brasilia, Brasilia, DF, Brasil

Elisa Ustarroz

PUCRS, Porto Alegre, RS, Brasil

\section{ISSN 2179-8435}



Este artigo está licenciado sob forma de uma licença Creative Commons Atribuição 4.0 Internacional, que permite uso irrestrito, distribuição e reprodução em qualquer meio, desde
seja corretamente citada. hitp://creativecommons.org/licenses/by/4.0/deed.pt_BP

\title{
A Educação do Campo no Estado do Espírito Santo: os movimentos sociais e a materialização das lutas
}

\author{
The education field in the State of Espírito Santo: \\ the social movements and the realization of struggles \\ Ramofly Bicalho $\oplus^{1}$ \\ Marizete Andrade Silva $\odot^{2}$ \\ ${ }^{1}$ Universidade Federal Rural do Rio de Janeiro, Seropédica, RJ, Brasil. \\ 2 Universidade Federal de Minas Gerais, Belo Horizonte, MG, Brasil.
}

\section{RESUMO}

O presente artigo tem como objetivos caracterizar a Educação do Campo no Espírito Santo, apresentando as experiências educacionais que se constitui como alternativa de resistência dos camponeses ao padrão de desenvolvimento estabelecido pelo capital, em uma estreita relação com a materialização das lutas travadas pelos movimentos sociais e a formação do educador nas escolas do campo, enquanto espaços de produção crítica, autônoma e emancipadora do conhecimento. A pesquisa documental foi desenvolvida, predominantemente, em acervos bibliográficos. Apoiamo-nos em uma perspectiva sociológica de investigação e explicação dos processos sociais de participação dos sujeitos camponeses, enquanto seres históricos e culturais. Entre as fontes de investigação, utilizamos legislações, portarias, decretos e referenciais teóricos sobre Educação do Campo, em especial, Arroyo e Fernandes (1999); Brandão (1984) e Caldart (2002). Dentre as iniciativas pesquisadas, destacamos: o Movimento de Educação Promocional do Espírito Santo (Mepes), as Escolas Comunitárias Rurais (Ecors), a Regional das Associações dos Centros Familiares de Formação em Alternância do Espírito Santo (Raceffaes), a Federação dos Trabalhadores na Agricultura no Espírito Santo (Fetaes), o Movimento dos Pequenos Agricultores (MPA), a Educação Indígena, Educação Quilombola e o Movimento dos Trabalhadores Rurais Sem Terra (MST). Compreendemos que essas entidades e movimentos sociais, há décadas presentes no Espírito Santo, com projetos vinculados ao campesinato capixaba, afirmam propostas pedagógicas sintetizadas a partir das contradições históricas que situam o homem e a mulher do campo como sujeitos de direitos. Nesse contexto, os elementos que movem o processo de ensino e de aprendizagem são retirados da realidade concreta e, desse modo, não há possibilidade de desvincular a luta pela terra e a educação, sejam quais forem os espaços em que essas experiências se materializam.

Palavras-chave: Educação do Campo. Movimentos sociais. Lutas camponesas. 


\section{ABSTRACT}

The objective of this article is to characterize the field education in Espírito Santo, presenting the educational experiences that constitute the peasants' alternative of resistance to the pattern of development established by capital, in close relation with the materialization of the struggles waged by social movements and formation of the educator in the rural schools, as spaces of critical, autonomous and emancipatory production of knowledge. Documentary research was developed, predominantly, in bibliographic collections. We support a sociological perspective of investigation and explanation of the social processes of participation of the peasant subjects, as historical and cultural beings. Among the sources of research, we use legislation, ordinances, decrees and theoretical references on rural education, especially Arroyo \& Fernandes, 1999; Brandão, 1984; Caldart, 2002. Among the initiatives researched, we highlight: Promotional Education Movement of Espírito Santo (MEPES), Rural Community Schools (ECORS), Regional of the Associations of Family Centers of Formation in Alternation of Espírito Santo (RACEFFAES), Federation of Workers in Agriculture in Espírito Santo (FETAES), Small Farmers' Movement (MPA), Indigenous Education, Quilombola Education and Movement of Landless Rural Workers (MST). We understand that these entities and social movements, for decades present in the Holy Spirit, with projects linked to the peasantry of Espírito Santo, affirm pedagogical proposals synthesized from the historical contradictions that place the rural man and woman as subjects of rights. In this context, the elements that move the process of teaching and learning are removed from the concrete reality and, in this way, there is no possibility of untying the struggle for land and education, regardless of the spaces in which these experiences materialize.

Keywords: Rural Education. Social movements. Peasant struggles.

\section{Introdução}

Tossa intenção com este trabalho é divulgar os primeiros resultados da Dissertação de Mestrado em Educação do 1 Campo, defendida no Programa de Pós-Graduação em Educação Agrícola (PPGEA) da Universidade Federal Rural do Rio de Janeiro (UFRRJ). A intenção deste artigo é compreender a problemática da Educação do Campo no estado do Espírito Santo e a sua estreita relação com a materialização das lutas travadas pelos movimentos sociais. Nos últimos anos muito tem se discutido sobre Educação do Campo, em especial, a influência do contexto urbano nos currículos, materiais didáticos e a formação dos educadores/as para as escolas campesinas. Neste campo de análise, privilegiamos as relações entre a educação do campo, a formação do educador e os movimentos sociais, considerando as práticas educativas que vão além dos processos tradicionais de escolarização, em um estreito diálogo entre os espaços institucionais, os processos sociais, culturais e políticos que constituem a sociedade brasileira. 
Esse é outro objetivo do texto, em um movimento de luta pela educação do campo, fortalecendo as identidades camponesas e preservando desejos, sonhos, trajetórias, valores e histórias de vida dos sujeitos envolvidos nesse processo.

Nessa conjuntura, a escola do campo pode se converter em espaços de produção crítica, autônoma e emancipadora do conhecimento, instrumento a serviço das camadas populares, com propostas educativas de emancipação humana e valorização dos diversos saberes. As escolas do campo e os seus educadores devem estar preparados para lidar com as diversas peculiaridades que abrangem a vida no campo, resgatando a cultura tradicional das/ dos trabalhadoras/es rurais, em contraposição ao intenso processo de urbanização, direcionado para os interesses de determinadas classes sociais. A supervalorização dos espaços urbanos pode ser etnocêntrica por estabelecer a cultura ocidental como parâmetro, privilegiando a racionalidade do capitalismo, vinculada ao avanço tecnológico e científico.

Neste texto mostraremos a relevância dos princípios desenvolvidos pelos movimentos sociais na luta "Por Uma Educação do Campo". Suas bandeiras, projetos, perspectivas e utopias. A formação política dos trabalhadores e a valorização da consciência social são alguns dos desafios. A produção de tal conhecimento pode ressignificar memórias, identidades e histórias vividas pelos sujeitos, articulados para superar a opressão que atinge milhares de camponeses/as. As reflexões em torno do movimento pela Educação do Campo no Brasil vêm identificando a necessidade constante de transformar o conhecimento em ação, registrando práticas pedagógicas e compreendendo as diversas experiências nas relações sociais e de trabalho.

Essas experiências podem contribuir, ainda, para gestação de embriões de democratização, socialização de poder, superação dos desafios, afirmação de identidades e seres humanos preocupados com o fortalecimento de ambientes coletivos. Nessas reflexões consideramos o campo como espaço de vida. Espaço que contribui para o desenvolvimento mais pleno do ser humano e da sua inserção consciente no contexto social do qual faz parte (CALDART, 2002). A realidade histórica de intensa desumanização que caracterizou a vida da população camponesa, gerou esse movimento em favor da Educação Básica do Campo. Uma realidade que, mesmo marcada por opressões e injustiças, continua reivindicando profundas e imediatas alterações sociais no campo brasileiro.

A luta dos movimentos sociais pelo direito à educação produziu inúmeras conquistas para educadores e educandos das escolas do campo. Segundo Caldart (2002), o movimento por uma educação do campo se vincula a outras lutas que garantam melhores condições de vida para a população camponesa. Conexão que se justifica pela impossibilidade de educar o povo sem modificar as condições que o desumaniza. Tal conexão representa a capacidade de articulação dos movimentos sociais e aponta para crescente necessidade de garantir projetos populares, cuja organização tenha como referência a cultura e o trabalho dos grupos sociais camponeses. O debate acerca da Educação 
do Campo deve, portanto, entender a complexidade da dimensão do campo brasileiro, constituído por paisagens, lutas, organicidade, desejos, histórias, memórias, identidades e modos de vida, reafirmando esse espaço e as lutas travadas pelos movimentos sociais na consolidação de projetos de educação popular emancipadora.

Neste artigo trabalharemos com os seguintes movimentos sociais: Centros Familiares de formação por alternância (Ceffas); Movimento de Educação Promocional do Espírito Santo (Mepes); Escolas Comunitárias Rurais (Ecors); Regional das Associações dos Centros Familiares de Formação em Alternância do Espírito Santo (Raceffaes); Federação dos Trabalhadores na Agricultura no Espírito Santo (Fetaes); Movimento dos Pequenos Agricultores (MPA); Educação Indígena; Educação Quilombola; e Movimento dos Trabalhadores Rurais Sem Terra $(\mathrm{MST})^{1}$.

\section{Material e métodos}

Nesta investigação utilizamos a pesquisa qualitativa, considerando o universo das crenças, valores, atitudes, motivações e histórias dos sujeitos individuais e coletivos. Ela permitiu uma inserção social mais profunda na realidade, explorando a diversidade de materiais bibliográficos vinculados aos movimentos sociais do campo no estado do Espírito Santo, além de legislações, decretos e portarias que tratam da Educação do Campo no Brasil, na sua estreita relação com as políticas públicas, formação docente, projeto político pedagógico, desenvolvimento socioeconômico e agricultura familiar, orgânica e agroecológica. No trabalho de campo conhecemos melhor os movimentos sociais estudados, tendo acesso a importantes documentos oficiais e interagindo com as comunidades pesquisadas nos encontros, reuniões, festas e demais eventos.

Esta pesquisa respondeu questões muito peculiares acerca da Educação do Campo nos movimentos sociais. Importante notar que a preocupação com a realidade não pode ser quantificada, visto que exploramos um universo de significações, conhecimentos, identidades, memórias, experiências, atitudes e crenças bem diversificadas. Com tal metodologia aprofundamos a compreensão da realidade, respeitando as experiências pessoais, sociais e comunitárias dos indivíduos, os seus coletivos e as vivências familiares.

A pesquisa qualitativa, descritiva e exploratória, com ênfase em pesquisa documental foi desenvolvida, predominantemente, em acervos bibliográficos. Utilizamos legislações, portarias, decretos e referenciais teóricos sobre Educação do Campo nos movimentos sociais como parte dos instrumentos de coleta de dados e fontes de

\footnotetext{
1 Estamos elaborando um artigo específico sobre educação do campo no Espírito vinculada ao Movimento dos Trabalhadores Rurais Sem Terra (MST).
} 
investigação para apresentação das experiências educacionais. Apoiamo-nos em uma perspectiva sociológica de investigação e explicação dos processos sociais de participação dos sujeitos camponeses, enquanto seres históricos e culturais.

Focalizamos as relações entre as histórias de vida das pessoas, no envolvimento com as lutas organizadas pelos movimentos sociais do campo, contribuindo para formação de novos sujeitos sociais, em uma perspectiva popular e histórica. Acreditamos nessa dimensão educativa e no fazer pedagógico que tais sujeitos realizam através da organização coletiva e no fortalecimento de projetos políticos pedagógicos emancipadores. Reiteramos a realização de um amplo levantamento de materiais bibliográficos e leituras interpretativas dos documentos que norteiam a Educação do Campo nos movimentos sociais. Importante ressaltar que a observação foi uma das técnicas utilizadas, em especial, por se tratar de uma pesquisa de campo na área de Ciências Humanas e Sociais. Embora seja uma técnica relativamente espontânea, a observação exige uma considerável sistematização de método, que a potencializa.

\section{Resultados}

A Educação do Campo é o resultado do acúmulo das experiências de diferentes sujeitos sociais nos seus territórios e temporalidades, constituindo uma extensa caminhada marcada por avanços e retrocessos, lutas e resistências dos/ das trabalhadoras/es camponeses. Representa a síntese de experiências socioeducativas que resistem às políticas de consolidação da sociedade marcadamente urbana e o fim das populações camponesas. Caracterizar a Educação do Campo no estado do Espírito Santo não é tarefa das mais fáceis. Nossa intenção é apresentar as experiências de participação dos movimentos sociais do campo no fortalecimento da luta por uma educação básica de qualidade para os camponeses.

Segundo Saldanha, Antongiovanni, Scarim (2009), no estado do Espírito Santo são identificadas as seguintes experiências de Educação do Campo: Centros Familiares de formação por alternância (Ceffas), Movimento de Educação Promocional do Espírito Santo (Mepes), Escolas Comunitárias Rurais (Ecors), Regional das Associações dos Centros Familiares de Formação em Alternância do Espírito Santo (Raceffaes), Federação dos Trabalhadores na Agricultura no Espírito Santo (Fetaes), Movimento dos Pequenos Agricultores (MPA), Educação Indígena, Educação Quilombola e Movimento dos Trabalhadores Rurais Sem Terra (MST). São entidades e movimentos sociais com propostas pedagógicas, materializadas nas contradições históricas, sem as quais, o campesinato capixaba, especialmente a agricultura familiar, não resistiria ao padrão de desenvolvimento imposto pelo capital. Assim, mesmo em um território com estrutura fundiária concentrada, os conflitos pela posse da terra e as restrições à execução de 
projetos de reforma agrária, emergiram experiências educacionais em contraposição ao avanço da territorialização do agronegócio.

A Educação do Campo no Espírito Santo não pode ser compreendida desvinculada do contexto das Escolas Famílias Agrícolas e da pedagogia da alternância, uma vez que não existem registros no Estado de outros projetos de educação popular voltados para os camponeses, anterior a tais experiências educacionais. Os agricultores encontraram nesse projeto de educação emancipatória, alternativas para o acesso e a permanência das crianças, jovens e adultos na escola. Essa concepção de educação, diferente da escola tradicional, valoriza os saberes oriundos das experiências vividas, as referências de cultura e trabalho, a relação entre agricultores e natureza, além de defender um calendário agrícola específico. Deste modo, a pedagogia da alternância retira da realidade, os elementos mais significativos do processo de ensino-aprendizagem. Diante dessa conjuntura, se faz importante conhecer as experiências dos movimentos sociais a seguir.

a) Os Centros Familiares de Formação por Alternância (Ceffas): com origem na França, em Lauzun, no ano de 1935. Eram as chamadas Maison Familiales Rurales. O primeiro centro foi idealizado por um grupo de agricultores e pelo padre Abbé Grannereau, período onde o meio rural foi profundamente afetado por uma crise de mercado, cujos reflexos foram identificados na intensa migração para os grandes centros urbanos. Os Ceffas contribuíram com as mudanças que o campo precisava, democratizando o acesso às tecnologias, enfrentando as questões relacionadas ao abandono das propriedades pelos jovens e um ensino regular, direcionado, quase que exclusivamente, para as atividades urbanas. Importante considerar que o êxito da pedagogia da alternância permitiu sua expansão para vários países da Europa, dentre eles: Alemanha e Portugal.

b) Movimento de Educação Promocional do Espírito Santo (Mepes): a primeira experiência de formação por alternância no Brasil foi no município de Anchieta, sul do Espírito Santo, em 1968, por iniciativa do padre Jesuíta Humberto Pietogrande, cuja formação pastoral foi influenciada pela Scuole Della Famiglia Rurale, região de Veneto, nordeste da Itália. O pároco articulou lideranças populares, religiosas e políticas para instituir o Mepes. Entidade filantrópica que criou a EFA de Olivania, primeira Escola Família Agrícola do Brasil. Atualmente o MEPES tem dezesseis escolas situadas nas regiões norte, sul e serrana do Espírito Santo, desenvolvendo atividades nas áreas de ação comunitária, saúde e educação. Presenciamos quinze escolas famílias localizadas em espaços campesinos e uma escola família de turismo, sediada no município de Piúma. Embora seja voltada para formação em hotelaria e gastronomia para o público urbano, apresenta a mesma filosofia e princípios metodológicos das EFAS.

Os fatores que contribuíram para o protagonismo do Espírito Santo na adoção de tal experiência educacional foram: combinar o modelo italiano e francês, a força do catolicismo mantida pelos imigrantes italianos, o diálogo 
com os movimentos eclesiais, além da crise socioeconômica da cafeicultura, levando muitos agricultores à falência e sua migração para outras regiões do país (SILVA, 2003). Já na década de 1970, através das mobilizações populares, inúmeros estados brasileiros e municípios capixabas aderiram à proposta educacional das Efas, apostando na melhoria da qualidade de vida do coletivo rural. Segundo Mészáros (2008, p. 102): "A única força capaz de contribuir positivamente para o novo processo de transformação é a própria educação, cumprindo com isso seu papel de órgão social $[\ldots] "$.

c) As Escolas Comunitárias Rurais (Ecors): com início em 1985, com a necessidade de lutar por escolas do campo próximas ao ambiente familiar dos agricultores, além de resistir ao avanço das estruturas produtivas predatórias do meio ambiente. O debate acerca da criação das Ecors se estendeu até o ano de 1989, com a criação do Movimento de Ação Social. Através deste movimento foram criadas, no município de Jaguaré, norte do Espírito Santo, três escolas comunitárias cujas propostas pedagógicas são orientadas pela pedagogia da alternância, como acontece nas escolas famílias. De acordo com Saldanha, Antongiovanni e Scarim (2009) o que dificulta as atividades das escolas comunitárias é a fragilidade do diálogo com o poder público, que resiste à implantação da pedagogia da alternância, especialmente, no que se refere à aceitação e o reconhecimento da família agricultora no sistema de gestão da instituição, um dos princípios básicos dessa proposta educacional.

Segundo Kolling, Ceriolli e Caldart (2002, p.20) "o povo que vive no campo tem que ser o sujeito de sua própria educação". É essa a lógica que orienta os movimentos sociais na luta pela Educação do Campo. Ao resistir a participação das famílias no processo educativo, o sistema formal de ensino, reafirma o seu compromisso histórico com a subordinação do campo à cidade, ao mesmo tempo que reconhece a existência de movimentos contestadores.

d) Regional das Associações dos Centros Familiares de Formação em Alternância do Espírito Santo - (Rraceffaes): entidade civil de caráter educacional e sem finalidade lucrativa. Suas atividades possuem estreito diálogo com os Ceffas, tendo os seguintes objetivos: manter os princípios pedagógicos e filosóficos da alternância, gestão dos centros familiares de formação e participação das famílias agricultoras. A Raceffaes desenvolve atividades em comum com os Ceffas, defendendo os seus interesses e promovendo a expansão da pedagogia da alternância. Atualmente os Ceffas estão espalhados por todo território do Espírito Santo, conforme o Quadro 1. 
Quadro 1. Classificação dos Ceffas tendo como referência a mantenedora e o nível de ensino

\begin{tabular}{|c|c|c|c|c|}
\hline Mantenedora & Escolas & Nível de ensino & Filiadas à Raceffaes & Região do Estado \\
\hline \multirow{17}{*}{ Mepes } & EFA de Rio Bananal & Fundamental & Sim & Norte \\
\hline & EFA do Km 41 - São Mateus & Fundamental & Sim & Norte \\
\hline & EFA de Pinheiros & Fundamental & Sim & Norte \\
\hline & EFA de Chapadinha - Nova Venécia & Médio Profissionalizante & Sim & Norte \\
\hline & EFA de Boa Esperança & Médio Profissionalizante & Sim & Norte \\
\hline & EFA de Vinhático - Montanha & Fundamental e Médio Profissionalizante & Sim & Norte \\
\hline & EFA do Bley - São Gabriel da Palha & Fundamental e Médio Profissionalizante & Sim & Norte \\
\hline & EFA de Jaguaré & Médio Profissionalizante & Sim & Norte \\
\hline & EFA de Alfredo Chaves & Fundamental & Não & Sul \\
\hline & EFA de Olivania, Anchieta & Fundamental e Médio Profissionalizante & Não & Sul \\
\hline & EFA de Castelo & Fundamental & Não & Sul \\
\hline & EFA de Campinho, Iconha & Fundamental & Não & Sul \\
\hline & EFA de Rio Novo do Sul & Fundamental & Não & Sul \\
\hline & $\begin{array}{l}\text { EFA São João do Garrafão - Santa } \\
\text { Maria de Jetibá }\end{array}$ & Fundamental & Não & Sul \\
\hline & EFA de Marilândia & Fundamental & Não & Sul \\
\hline & EFA de Belo Monte, Mimoso do Sul & Fundamental & Não & Sul \\
\hline & Escola Família de Turismo - Anchieta & Médio Profissionalizante & Não & Sul \\
\hline \multirow{10}{*}{$\begin{array}{l}\text { Governo } \\
\text { Municipal }\end{array}$} & EFA de Barra de São Francisco & Fundamental & Sim & Norte \\
\hline & $\begin{array}{l}\text { EFA Jacira de Paula Meniguete - } \\
\text { Barra de São Francisco }\end{array}$ & Fundamental & Sim & Norte \\
\hline & ECOR de Japira - Jaguaré & Fundamental & Sim & Norte \\
\hline & ECOR Família Rural de Ecoporanga & Fundamental & Sim & Norte \\
\hline & ECOR de Giral - Jaguaré & Fundamental & Sim & Norte \\
\hline & ECOR de São João Bosco - Jaguaré & Fundamental & Sim & Norte \\
\hline & EFA de Mantenópolis & Fundamental & Sim & Norte \\
\hline & EFA Agroecológica de Colatina & Fundamental & Sim & Norte \\
\hline & $\begin{array}{l}\text { EFA de São Bento do Chapéu - } \\
\text { Domingos Martins }\end{array}$ & Fundamental & Não & Serrana \\
\hline & EFA de Brejetuba & Fundamental & Não & Serrana \\
\hline
\end{tabular}

Fonte: Mepes, Raceffaes, 2014. 
e) Federação dos Trabalhadores na Agricultura do Estado do Espírito Santo (Fetaes): tem 45 anos de existência. Apresenta em seu quadro social 54 sindicatos e 19 extensões de base, abrangendo mais de 98\% do território capixaba. Sua organização interna é composta de secretarias responsáveis por áreas elementares para os trabalhadores rurais: formação de lideranças, educação, crédito rural, organização de jovens, reforma agrária, associativismo, cooperativismo, habitação, previdência social, sindicalização, entre outros espaços de atuação. Dentre as experiências desenvolvidas pela Fetaes na área de educação destaca-se: a implementação do projeto de capacitação voltado para o Desenvolvimento Territorial Sustentável, através de convenio com o Ministério de Desenvolvimento Agrário - MDA. Essa iniciativa tem como público-alvo as lideranças comunitárias e os dirigentes sindicais. Importante salientar ainda os convênios com o Ministério da Educação (MEC) na capacitação dos educadores do campo (FETAES, 2015).

f) Movimento dos Pequenos Agricultores (MPA): este movimento camponês surge no final de 1995, Rio Grande do Sul. Ele é resultante da crise enfrentada pelos sindicatos que, após desempenhar um papel importante na luta camponesa, acabou se envolvendo com a burocracia estatal. Hoje o MPA está presente em mais de 17 estados com expressivos avanços no plano camponês, projeto com dois eixos bem específicos: condições para produzir e viver bem no campo. No âmbito educacional, esse plano defende o direito à educação básica e ao ensino superior para os povos camponeses. Lutam por universidades públicas acessíveis aos trabalhadores/as do campo, considerando a realidade camponesa. Propõe escolas do campo próximas às famílias e conteúdos curriculares em conformidade com às necessidades dos sujeitos, individuais e coletivos.

O movimento entende que as atividades desenvolvidas cotidianamente entre os camponeses, podem contribuir para o aprendizado de novas práticas e saberes, priorizando debates, encontros, oficinas, reuniões de grupo e outras formas de organização que possibilitem à valorização do conhecimento popular e da educação informal. O projeto popular idealizado pelo MPA junto aos agricultores familiares, valoriza o modo de vida camponês, nas suas diversas manifestações: organização da produção, reestruturação fundiária, desenvolvimento rural sustentável, política agrícolas, segurança alimentar e um novo modelo tecnológico. (MPA, 2010). Para Mészáros (2008, p. 53):

Nunca é demais salientar a importância estratégica da concepção mais ampla de educação, expressa na frase: "a aprendizagem é nossa própria vida". Pois muito do nosso contínuo de aprendizagem se situa, felizmente, fora das instituições educacionais formais. Felizmente, porque esses processos não podem ser manipulados e controlados de imediato pela estrutura educacional formal legalmente salvaguarda e sancionada.

Importante ressaltar algumas das experiências de Educação do Campo no Espírito Santo, desenvolvidas pelo MPA: 1) Projetos de Educação de Jovens e Adultos (EJA) em parceria com a rede estadual de ensino, em sua grande 
maioria com educandos/as do município de São Gabriel da Palha - ES. O movimento tem em seu cadastro mais de 10 turmas, com cerca de 120 estudantes. As atividades são trabalhadas a partir de temas geradores e subtemas, valorizando as histórias de vida e trajetórias dos sujeitos na estreita relação com o campesinato; 2) Tem parceria com as escolas famílias agrícolas (EFAs) na formação de quadros; e 3) Estabeleceu parceria com a Universidade Federal do Espírito Santo (UFES), na elaboração de projetos que atendam as demandas das populações camponesas no ensino superior, através das Licenciaturas em Educação do Campo (MPA, 2014).

g) Educação Escolar Quilombola no Espírito Santo: desde a década de 1980 vários representantes de organizações e comunidades quilombolas estão presentes na defesa por uma educação que valorize o campo brasileiro. Apesar da histórica trajetória de lutas por melhores condições de ensino nas escolas do campo localizadas em territórios quilombolas, as estruturas físicas dessas instituições educacionais nas comunidades quilombolas do estado, estão em condições de intensa precariedade. Além das inadequações estruturais, os povos tradicionais convivem com inúmeras dificuldades no desenvolvimento da agricultura familiar, em algumas regiões do norte capixaba e o agravante das propriedades quilombolas cada vez mais reduzidas, em decorrência do avanço das grandes empresas de monocultura. Para Gomes (2005, p. 26):

O projeto da Aracruz Celulose, por ter sido acompanhado das grandes plantações exigidas pela monocultura do eucalipto, acabou por gerar problemas ainda mais sérios na vida rural e, também nas cidades, uma vez que a concentração de terras, desapropriadas muitas vezes com violência das famílias camponesas, afasta cada vez mais as oportunidades de trabalho, forçando as migrações. [...] A principal contribuição do governo estadual ao Grupo Aracruz foi o reconhecimento da posse de terras, antes ocupadas pela agricultura familiar, cultura indígena e remanescentes quilombolas.

Muitos jovens da região conhecida como Sapê do Norte $^{2}$, interrompem seus estudos para trabalharem nas empreiteiras de produção de álcool, aumentando consideravelmente os índices de evasão escolar nestas comunidades. A situação é ainda mais alarmante nos níveis mais elevados de ensino. A oportunidade de frequentar o ensino superior é muito rara, menos de uma dezena de educadoras da região do Sapê do Norte concluíram a Licenciatura em Pedagogia (NASCIMENTO, 2009). Para minimizar este quadro, a Federação de Órgãos para

2 Denominação da região fronteiriça entre os estados do Espírito Santo e da Bahia, que abrange os municípios de Conceição da Barra e São Mateus, norte do estado. Ocupada tradicionalmente por 32 comunidades quilombolas originados de grandes levas de negros africanos escravizados, que durante o século XIX desembarcavam no Porto de São Mateus designados ao trabalho nas fazendas produtoras da farinha de mandioca. 
Assistência Social e Educacional (Fase), entidade capixaba, desenvolve parcerias com as comunidades quilombolas, fortalecendo as instituições educacionais e ações que contemplem as experiências de educação do campo no estado. A Escola Quilombola Popular de Educação Política e Ambiental ${ }^{3}$, parceira desse projeto, é referência na denúncia das consequências econômicas, ambientais e socioculturais provocadas pelo cultivo do eucalipto, base do modelo de desenvolvimento imposto na região.

h) Educação Escolar Indígena: está expressivamente vinculada à questão fundiária do Espírito Santo. Todo processo de construção das escolas nas aldeias Tupinikim e Guarani ${ }^{4}$ não pode ser compreendido distante da luta pela terra. Essas aldeias conseguiram, após amplo debate com os órgãos governamentais e não governamentais, obter avanços importantes no âmbito da educação escolar. Segundo Teao (2008) a experiência de educação escolar indígena no Espírito Santo, teve o seu início com a EJA em 1994, sob orientação da Pastoral Indigenista. Seus principais objetivos foram: alfabetização, educação da mulher, educação sanitária, artesanato e educação agrícola. Todavia, mesmo com as particularidades de cada cultura, como é o caso destas duas etnias, as políticas públicas, em sua grande maioria, são niveladoras, restringindo a consolidação da educação popular. Para Arroyo (1999, p. 30) "pensar uma proposta de educação básica do campo supõe superar esta visão homogeneizadora e depreciativa e avançar para uma visão positiva".

i) Educação do Campo no Espírito Santo: muitas iniciativas foram tomadas pelo poder público, através da mobilização popular para implementação de políticas públicas e programas que ampliem as experiências de Educação do Campo no Espírito Santo. Muitas dessas iniciativas são ações desenvolvidas em parceria com a Universidade Federal do Espírito Santo (UFES) e os movimentos sociais. No ano de 1989, por meio do Centro de Desenvolvimento dos Assentados e Pequenos Agricultores do Estado do Espírito Santo (Cidap), foram implantados cursos de extensão nas áreas de Agronomia, Pedagogia e Administração. Em julho de 1995 foi celebrado convênio entre o MST, a Secretaria Estadual de Educação (Sedu) e a Ufes, instituindo o Curso de Habilitação para o Magistério. Ainda em parceria com a Universidade, através do Convênio de no 2001/1999, publicado no Diário Oficial da União - DOU em 08/11/1999, foi criado o Curso de Pedagogia da Terra, formando em nível superior, centenas de educadores do campo no Estado.

3 Projeto que abrange mais de 10 comunidades remanescentes quilombolas, do Norte do Espírito Santo, para um fim de semana de troca de experiências e saberes. Os temas que a equipe da Fase traz para discussão variam e também são muito contemporâneos. Nesses encontros a perspectiva trazida pelos quilombolas do Sapê do Norte revela a ancestralidade, a relação com a terra e a cultura tradicional.

4 De acordo com o censo da Funai (2010) existem no Espírito Santo, aproximadamente, 2.880 indígenas aldeados, sendo que 301 pertencentes a etnia Guarani e 2.579 da Tupinikim. Ambas situadas no município de Aracruz, distante $83 \mathrm{Km}$ da capital, Vitória. As aldeias Guarani são: Mboapy Pindo, Tekoa Porã e Piraquê-Açu. As aldeias Tupinikim são: Pau Brasil, Caieiras Velhas, Irajá e Comboios. 
O fortalecimento da luta por educação para os diferentes sujeitos do campesinato capixaba, apresenta ainda como referência o Comitê Estadual de Educação do Campo, oficializado em 2008 no Seminário Estadual "Educação Escolar do Campo". Trata-se de uma organização constituída pelos movimentos sociais com o objetivo de promover debates coletivos, articulações e deliberações sobre a Educação do Campo. A atuação desse Comitê junto aos movimentos sociais foi primordial para criação do Curso de Licenciatura em Educação do Campo na Universidade Federal do Espírito Santo, em cumprimento à Resolução CNE/CEB no 1, de 03/04/2002 e o Decreto no 7.352 de 04/11/2010, em conformidade com o Programa Nacional de Educação do Campo (Pronacampo). Esse curso está vinculado, pedagógica e administrativamente, ao Centro Universitário Norte do Espírito Santo (Ceunes/Ufes), atendendo demandas da Região Norte do Espírito Santo, Leste de Minas Gerais e Extremo Sul da Bahia (BICALHO; SILVA, 2016).

Os movimentos sociais capixabas em diálogo com a Licenciatura em Educação do Campo da Ufes possuem os seguintes desafios: expandir a formação dos educadores que atuam nas escolas do campo, enfrentando o poder público quanto ao fechamento das escolas do campo no Estado. Segundo dados apresentados nos Quadros 2 e 3 da Secretaria Estadual de Educação (SEDU, 2012), nos últimos 12 anos, a rede estadual fechou 499 escolas do campo.

Quadro 2. Fechamento de escolas municipais - ES

\begin{tabular}{|l|c|c|c|}
\hline \multirow{2}{*}{ Municípios } & \multicolumn{2}{|c|}{ Total de escolas municipais } & \multirow{2}{*}{ Escolas fechadas } \\
\hline Afonso Cláudio & $\mathbf{1 9 9 8 - 2 0 1 0}$ & $\mathbf{2 0 1 0}$ & 41 \\
\hline Água Doce do Norte & 70 & 29 & 41 \\
\hline Alegre & 47 & 06 & 48 \\
\hline Barra de São Francisco & 78 & 30 & 54 \\
\hline Castelo & 68 & 14 & 48 \\
\hline Colatina & 59 & 11 & 69 \\
\hline Ecoporanga & 103 & 34 & 79 \\
\hline Ibitirama & 101 & 22 & 45 \\
\hline Mantenópolis & 53 & 08 & 36 \\
\hline Muniz Freire & 49 & 13 & 40 \\
\hline Nova Venécia & 65 & 25 & 56 \\
\hline São Mateus & 95 & 39 & 200 \\
\hline 69 Municípios & 265 & 65 & 1744 \\
\hline
\end{tabular}

Fonte: SEDU-ES, 2012. 
Quadro 3. Fechamento de escolas estaduais - ES

\begin{tabular}{|l|c|c|c|}
\hline \multirow{2}{*}{ Municípios } & \multicolumn{2}{|c|}{ Total de escolas estaduais } & \multirow{2}{*}{ Escolas fechadas } \\
\hline Afonso Cláudio & $\mathbf{1 9 9 8 - 2 0 1 0}$ & $\mathbf{2 0 1 0}$ & 17 \\
\hline Baixo Guandu & 17 & 0 & 16 \\
\hline Barra de São Francisco & 16 & 0 & 32 \\
\hline Cachoeiro de Itapemirim & 34 & 5 & 26 \\
\hline Colatina & 31 & 0 & 27 \\
\hline Linhares & 27 & 3 & 54 \\
\hline Mimoso do Sul & 57 & 2 & 30 \\
\hline Montanha & 32 & 4 & 15 \\
\hline Nova Venécia & 19 & 5 & 29 \\
\hline Rio Bananal & 34 & 0 & 14 \\
\hline São Domingos do Norte & 14 & 0 & 14 \\
\hline São Mateus & 14 & 4 & 23 \\
\hline 76 municípios & 27 & 65 & 499 \\
\hline
\end{tabular}

Fonte: SEDU-ES, 2012.

A rede municipal fechou 1.744. Um total de 2.243 escolas fechadas no estado do Espírito Santo. Inadmissível esses números. Importante registrar que 69 municípios fecharam escolas entre os anos de 1998 e 2010. A rede estadual agiu da mesma forma com a população campesina, em 32 municípios.

Esses dados revelam que, apesar das inúmeras experiências educacionais importantes e das denúncias feitas pelos movimentos sociais no estado, o cenário de descaso do campo capixaba é preocupante. É estratégico ressaltar que o estímulo ao fechamento das escolas do campo se consolida com as políticas de transporte escolar e nucleação das escolas. Essas medidas arbitrárias das gestões públicas impõem aos educandos uma exaustiva jornada diária às escolas da cidade. Em muitos casos, a garantia de prestação do serviço ao poder público não atende à qualidade do transporte escolar e viola direitos básicos dos educandos: o desenvolvimento de processos educativos que contemple a sua inserção nas comunidades.

Para Arroyo (1999) a escola deve interpretar os processos educativos que acontecem fora dela, organizando conhecimentos, socializando saberes e culturas historicamente produzidas, além de intervir na realidade, a partir dos instrumentos técnico-científicos. Certamente o estudante que reside no campo e estuda na cidade, interpreta 
os fenômenos da vida desvinculados de sua realidade. Ao invés de lutarem pelas histórias, identidades e memórias que compõem as comunidades campesinas e o jeito de ser dos sujeitos camponeses, preferem abandonar o campo em direção aos grandes centros urbanos. Nessa conjuntura, destacamos a importância dos movimentos sociais do campo na resistência e organização de ações que consolidem as experiências pedagógicas dos povos capixaba.

\section{Considerações finais}

Considerando a perspectiva pedagógica, destacamos que a Educação do Campo não pode ser compreendida distante das políticas públicas de formação dos sujeitos e da organização de uma outra sociedade. A construção de projetos populares do campo pode revelar desafios para os movimentos sociais, em especial, a necessidade de dialogar com os órgãos do governo. Historicamente, o estado brasileiro dispensou qualquer representatividade dos povos camponeses na idealização e consolidação de suas políticas e programas. Quando os sujeitos camponeses não são representados na elaboração das políticas, elas se tornam homogeneizadoras e os seus objetivos incompatíveis com as demandas do campo. Ressaltamos, então, a importância da organização popular para cobrar do Estado a efetivação dos compromissos históricos com os povos camponeses.

A Educação do Campo no Brasil, historicamente, foi tratada como Educação Rural. Por muito tempo subjugada aos interesses das classes privilegiadas, reflexo das adaptações, valores e princípios das escolas urbanas. Mesmo com o advento da Lei de Diretrizes e Bases da Educação Nacional (9394/96) e a implementação, em 2002, das Diretrizes Operacionais da Educação Básica do Campo, na prática, mudar profundamente as escolas camponesas, ainda é um enorme desafio. As escolas do campo podem ser protagonistas na promoção do desenvolvimento das comunidades camponesas, em uma perspectiva contra-hegemônica, de socialização das novas gerações e da produção emancipadora do conhecimento, valorizando a agricultura familiar, as religiosidades, a formação étnica, o respeito à historicidade, à memória coletiva, à identidade camponesa e os saberes sociais. Todo um processo de construção que vai além das finalidades, tradicionalmente conservadoras, reservadas à escola (BICALHO, 2017).

A Educação do Campo pode representar a efetivação do projeto de educação popular defendido pelos trabalhadores/as camponeses. Com as suas histórias de vida, lutas e organizações político-sociais impactam a comunidade. Nesse sentido, afirmamos a necessidade de compreender os processos educativos na sua estreita relação com os interesses políticos, sociais e culturais dos grupos sociais. O desafio dos movimentos sociais é integrar os saberes camponeses à matriz curricular das escolas. Para tanto, é imprescindível desenvolver leituras críticas acerca dos valores urbanos presentes na organização curricular das escolas do campo. Tais valores podem comprometer 
a realidade camponesa. Para Arroyo (1999, p. 31): "A escola tem que ser mais rica, tem que incorporar o saber, a cultura, o conhecimento socialmente construído [...]."

Importante registrar o empenho dos sujeitos, individuais e coletivos, na defesa de currículos que dialoguem com a identidade das comunidades camponesas. Essas conquistas coletivas podem assegurar espaços democráticos e exercícios de autonomia, contribuindo na contextualização dos educandos e no reconhecimento de suas práticas educativas. Valoriza-se a produção do saber, considerando as áreas de conhecimentos, rompendo com o processo de disciplinarização dos conteúdos, de responsabilidade individual dos educadores. Inclusive, a formação dos sujeitos educadores, foi outro aspecto considerado nesse contexto. É preciso prepará-los para o compromisso coletivo com a transformação social, sendo agentes promotores de uma educação popular do campo que permita superar a precariedade dos muitos espaços campesinos. Urgente ainda: 1) a implementação de políticas de valorização desses trabalhadores, através do cumprimento da Lei do Piso Nacional para os profissionais do magistério; 2) enfrentar a altíssima rotatividade dos docentes nas escolas do campo; e 3) formação continuada dos educadores, considerando as especificidades da educação do campo (BICALHO, 2016, 2017).

Mesmo sob condições adversas, ressaltamos que a Educação do Campo no estado do Espírito Santo possui experiências bastante ricas, em especial, a sua articulação com os movimentos sociais e outras lutas camponesas, considerando as reais necessidades dos sujeitos envolvidos. Importante novamente registrar que o movimento pela Educação do Campo vem, historicamente, reivindicando políticas públicas específicas e tem a sua gênese no protagonismo das organizações e movimentos sociais. À medida que se eleva a consciência do povo sobre os seus direitos, novas políticas públicas são exigidas, justificando a organização e o engajamento dos movimentos sociais nessa luta. Para Arroyo (2004, p. 60) "são esses movimentos os grandes educadores coletivos da nova consciência política dos direitos".

\section{Referências}

ARROYO, Miguel. A educação Básica e o movimento social do campo. In: ARROYO, Miguel; FERNANDES, Bernardo Mançano. A educação Básica e o movimento social do campo: Por uma educação básica do campo. Articulação Nacional por uma Educação Básica do Campo, Brasília, p. 13-52, 1999. https://doi.org/10.11606/t.96.2014.tde-21072014-164259

BICALHO, Ramofly. Possíveis Interfaces entre Educação do Campo, Educação Popular e Questões Agrárias. Curitiba: Appris, 2017. v. 1.234 p.

BICALHO, Ramofly; SILVA, M. A. Políticas públicas em educação do campo: PRONERA, PROCAMPO e PRONACAMPO. Revista Eletrônica de Educação, São Carlos, v. 10, n. 2, p. 135-144, 2016. https://doi.org/10.14244/198271991782 
BICALHO, Ramofly. Interfaces entre escolas do campo e movimentos sociais no Brasil. Revista Brasileira de Educação do Campo, Tocantinópolis, v. 1, n. 1, p. 26-46, jan./jun., 2016. https://doi.org/10.20873/uft.2525-4863.2016v1n1p26

BICALHO, Ramofly. Os movimentos sociais do campo e a formação do educador. Textura, Canoas, v. 18, n. 17, p. 5-26, maio/ago., 2016. https://doi.org/10.14393/rep-v17n22018-art02

BICALHO, Ramofly. História da Educação do Campo no Brasil: o protagonismo dos movimentos sociais. Teias (Rio de Janeiro), v. 18, n. 51, p. 210-224, (out./dez.), 2017. https://doi.org/10.12957/teias.2017.24758

BOGO, Ademar. Identidade e Luta de Classes. 2. ed. São Paulo: Expressão Popular, 2010.

BRANDÃO, Carlos Rodrigues. Educação Popular. São Paulo: Brasiliense, 1984.

BRASIL. Constituição (1988). Decreto no 7352, de 04 de novembro de 2010. Dispõe sobre a política de educação do campo e o Programa Nacional de Educação na Reforma Agrária - PRONERA. Disponível em: http://www.planalto.gov.br. https://doi. org/10.9771/gmed.v9i2.20647

CONSELHO ESTADUAL DE EDUCAÇÃO DO ESTADO DO ESPÍRITO SANTO. Resolução 56/92 e Parecer no 132/92. Aprova a criação das turmas de 5a a 8ª séries nas escolas de Assentamentos e o funcionamento da Pedagogia da Alternância). https://doi. org/10.20873/uft.rbec.e7129

CONSELHO NACIONAL DE EDUCAÇÃO. Câmara de Educação Básica. Resolução no 01 , de 03 de abril de 2002. Institui Diretrizes Operacionais para a Educação Básica nas Escolas do Campo. Disponível em: http://portal.mec.gov.br. https://doi. org/10.1590/s1413-24782012000100012

FEDERAÇÃO DOS TRABALHADORES NA AGRICULTURA NO ESTADO DO ESPÍRITO SANTO. Políticas Sociais. Disponível em: http://www.fetaes.org.br. Acesso em: 16 fev. 2015.

FRANÇA, Dalva Mendes de. Vivências da Pedagogia do Movimento em Escolas de Assentamento MST/ES. 2013. 270f. Dissertação (Mestrado em Educação) - Centro de Educação, Universidade Federal do Espírito Santo, Vitória, 2013. https://doi. org/10.20873/uft.rbec.e7334

FREIRE, P. Educação e mudança. Rio de Janeiro: Paz e Terra, 1979.

INCRA/CIDAP/UFES. Convênio no 2001/1999. DOU 08/11/1999.

KOLLING, E. J.; CERIOLI, P. R.; CALDART, R. S. Educação do Campo, identidade e políticas públicas. Brasília, DF. Articulação nacional por uma Educação do Campo, 2002. (Coleção Por Uma Educação do Campo, no 4). https://doi.org/10.20873/ uft.2525-4863.2018v3n3p862 
MÉSZÁROS, I. A educação para além do capital. Tradução de Isa Tavares. São Paulo: Boitempo, 2008. https://doi.org/10.5380/ nesef.v2i2.54651

MOVIMENTO DOS PEQUENOS AGRICUlTORES. Plano Camponês. Disponível em: http://www.mpabrasil.org.br. Acesso em: 16 fev. 2015.

NASCIMENTO, Olindina Serafim. Proposta de Educação Quilombola para as escolas das comunidades quilombolas do Sapê do Norte. In: SIMPÓSIO BRASILEIRO DE POLÍTICA E ADMINISTRAÇÃO DA EDUCAÇÃO, 24.; CONGRESSO INTERAMERICANO DE POLÍTICA E ADMINISTRAÇÃO DA EDUCAÇÃO, 2009, Vitória. Cadernos Anpae, n. 8. Vitória: Associação Nacional de Política e Administração da Educação, 2009. Disponível em: http://www.anpae.org.br/congressos_antigos/ simposio2009/index.html. Acesso em: 23 fev. 2014. https://doi.org/10.21573/vol32n012016.62376

PASSADOR, Claúdia Souza. A educação rural no Brasil: o caso da escola do campo do Paraná. São Paulo: Annablume, 2006.

SALDANHA, J. C; ANTONGIOVANNI, L; SCARIM, P. C. Diálogos entre a multifuncionalidade da agricultura familiar e os projetos coletivos da educação do campo e da agroecologia no norte do Espírito Santo. In: CAZELLA, A. A; BONNAL, P.; MALUF, R. S. Agricultura familiar: multifuncionalidade e desenvolvimento territorial no Brasil. Rio de Janeiro: Mauad X, 2009. p. 137-166. https://doi.org/10.5007/2175-7984.2009v8n14p211

SILVA, L. H. da. As experiências de formação de jovens do campo: alternância ou alternâncias. Viçosa: Editora UFV, 2003. https://doi.org/10.24824/978858042368.6

SOUZA, A. P.; PIZETTA, A. J. A formação do campesinato e as mudanças recentes na agricultura capixaba. In: SOUZA, A. P.; PIZETTA, A. J. A Reforma Agrária e o MST no ES: 20 anos de lutas, sonhos e conquistas de dignidade! Vitória/ES: MST, 2005.

STRECK, Danilo Romeu. Práticas educativas e movimentos sociais na América Latina: aprender nas fronteiras. Séries Estudos, Campo Grande: UCB, n. 22, p.99-112 jul./dez. 2006b.

TEAO, K. M. Formação de professores Tupinikim e Guarani Mbya do Espírito Santo. Cadernos de Educação Escolar Indígena, v. 6, p. 101-121, 2008.

Recebido em: 17/4/2018.

Aprovado em: 10/8/2019.

Publicado em: 31/12/2019. 


\section{Endereços para correspondência:}

Ramofly Bicalho

Universidade Federal Rural do Rio de Janeiro (UFRRJ)

Rodovia BR 465, Km 07, s/n - Zona Rural

23890-000, Seropédica, RJ, Brasil

\section{Autores:}

\section{RAMOFLY BiCALHO}

Universidade Federal Rural do Rio de Janeiro

Orcid: https://orcid.org/0000-0003-0571-6481

E-mail: ramofly@gmail.com

\section{Marizete Andrade Silva}

Universidade Federal de Minas Gerais.

Orcid: https://orcid.org/0000-0001-5901-6814

E-mail: marizethandrade@hotmail.com

Endereço: Universidade Federal de Minas Gerais (UFMG)

Av. Pres. Antônio Carlos, 6627 - Pampulha

31270-901, Belo Horizonte, MG, Brasil 